\title{
Processing characteristics of dairy cow milk are moderately heritable
}

\author{
G. Visentin, ${ }^{*} \dagger$ S. McParland,† M. De Marchi, ${ }^{*}$ A. McDermott, ${ }^{*} \dagger$ M. A. Fenelon, $\ddagger$ M. Penasa, ${ }^{*}$ and D. P. Berry ${ }^{1}$ \\ *Department of Agronomy, Food, Natural Resources, Animals and Environment (DAFNAE), University of Padova, Viale dell'Università 16, \\ 35020 Legnaro (PD), Italy \\ †Animal and Grassland Research and Innovation Center, Teagasc, Moorepark, Fermoy, Co. Cork, Ireland \\ $\ddagger$ Teagasc Food Research Center, Moorepark, Fermoy, Co. Cork, Ireland
}

\section{ABSTRACT}

Milk processing attributes represent a group of milk quality traits that are important to the dairy industry to inform product portfolio. However, because of the resources required to routinely measure such quality traits, precise genetic parameter estimates from a large population of animals are lacking for these traits. Milk processing characteristics considered in the present study-rennet coagulation time, curd-firming time, curd firmness at 30 and 60 min after rennet addition, heat coagulation time, casein micelle size, and milk $\mathrm{pH}$ - were all estimated using mid-infrared spectroscopy prediction equations. Variance components for these traits were estimated using 136,807 test-day records from 5 to $305 \mathrm{~d}$ in milk (DIM) from 9,824 cows using random regressions to model the additive genetic and within-lactation permanent environmental variances. Heritability estimates ranged from $0.18 \pm 0.01$ (26 DIM) to $0.38 \pm 0.02(180 \mathrm{DIM})$ for rennet coagulation time; from $0.26 \pm 0.02(5 \mathrm{DIM})$ to $0.57 \pm 0.02$ (174 DIM) for curd-firming time; from $0.16 \pm 0.01$ (30 DIM) to $0.56 \pm 0.02(271 \mathrm{DIM})$ for curd firmness at $30 \mathrm{~min}$; from $0.13 \pm 0.01$ (30 DIM) to $0.48 \pm 0.02$ (271 DIM) for curd firmness at $60 \mathrm{~min}$; from $0.08 \pm 0.01$ (17 DIM) to $0.24 \pm 0.01$ (180 DIM) for heat coagulation time; from $0.23 \pm 0.02(30 \mathrm{DIM})$ to $0.43 \pm 0.02$ (261 DIM) for casein micelle size; and from $0.20 \pm 0.01$ (30 DIM) to $0.36 \pm 0.02$ (151 DIM) for milk $\mathrm{pH}$. Within-trait genetic correlations across DIM weakened as the number of days between compared intervals increased but were mostly $>0.4$ except between the peripheries of the lactation. Eigenvalues and associated eigenfunctions of the additive genetic covariance matrix for all traits revealed that at least the $80 \%$ of the genetic variation among animals in lactation profiles was associated with the height of the lactation profile. Curd-firming time and curd firmness at 30 min were weakly to moder-

Received January 25, 2017.

Accepted April 10, 2017.

${ }^{1}$ Corresponding author: donagh.berry@teagasc.ie ately genetically correlated with milk yield (from 0.33 \pm 0.05 to $0.59 \pm 0.05$ for curd-firming time, and from $-0.62 \pm 0.03$ to $-0.21 \pm 0.06$ for curd firmness at 30 min). Milk protein concentration was strongly genetically correlated with curd firmness at $30 \mathrm{~min}(0.84 \pm$ 0.02 to $0.94 \pm 0.01)$ but only weakly genetically correlated with milk heat coagulation time $(-0.27 \pm 0.07$ to $0.19 \pm 0.06)$. Results from the present study indicate the existence of exploitable genetic variation for milk processing characteristics. Because of possible indirect deterioration in milk processing characteristics due to selection for greater milk yield, emphasis on milk processing characteristics is advised.

Key words: milk coagulation, milk quality, milk technological, spectrometry, random regression

\section{INTRODUCTION}

The importance of milk composition and udder health in the production of dairy products is generally well accepted (Williams, 2003; Murphy et al., 2016). Such importance underpins the inclusion of both milk composition and udder health in several dairy cow breeding objectives globally (Miglior et al., 2005). However, milk processability, which dictates the potential of transforming milk into different dairy products such as cheese and milk powder, is also an important characteristic of milk composition. Despite this, milk processability is not explicitly considered in national dairy cow breeding objectives.

Indicators of milk processability are commonly referred to as milk coagulation properties and these include rennet coagulation time (RCT, min), curd-firming time $\left(\mathbf{k}_{\mathbf{2 0}}, \mathbf{m i n}\right)$, curd firmness $30\left(\mathbf{a}_{\mathbf{3 0}}, \mathbf{m m}\right)$ and 60 $\left(\mathbf{a}_{60}, \mathrm{~mm}\right) \mathrm{min}$ after rennet addition, and heat coagulation time (HCT, min), casein micelle size (CMS, nm), and milk $\mathrm{pH}$. Several factors are known to contribute to variability in milk processing characteristics such as cow breed (De Marchi et al., 2007; Poulsen et al., 2013; Chen et al., 2016), stage of lactation (Ikonen et al., 2004; Barłowska et al., 2014), parity number (Ikonen et al., 1999; Tyrisevä et al., 2004), and the diet ingested 
(Reid et al., 2015). The existence of genetic variation in milk coagulation properties has been documented in several Holstein-Friesian populations, including populations in Italy (1,042 cows, Cassandro et al., 2008), Estonia (4,191 cows, Vallas et al., 2010; 5,216 cows, Pretto et al., 2014), Denmark (357 cows; Poulsen et al., 2015), and Finland (399 cows, Tyrisevä et al., 2004). These studies, however, have been limited in size, contributing to large associated standard errors of the estimated (co) variance components, and they have estimated genetic parameters of milk coagulation properties using repeatability animal models. The exceptions to the latter are Vallas et al. (2010) and Pretto et al. (2014), which used random regression animal models. To our knowledge, no study has attempted to quantify the existence of genetic variation in either HCT or CMS in dairy cows.

Large-scale recording of milk processing traits is often hampered by the associated resources necessary to undertake the reference methodologies. This not only limits the data set sizes to estimate precise genetic parameters, but also precludes the implementation of breeding strategies to improve these characteristics directly. Milk mid-infrared spectroscopy has been proposed as a phenotyping tool for a multitude of animal characteristics (Bastin et al., 2016; McParland and Berry, 2016) and milk quality traits (De Marchi et al., 2014), including milk processing attributes (Visentin et al., 2015). One of the main advantages of mid-infrared spectroscopy is that, once developed, new prediction models can be applied to historical spectral data for the prediction of novel traits at no additional cost.

Therefore, the objective of the present study was to quantify the genetic variation in milk processing characteristics and their correlations with milk-related performance traits using random regression models fitted across lactation. Results of the present study will provide greater and more precise knowledge of the extent of genetic variability that exists in milk processing characteristics and how this changes across lactation.

\section{MATERIALS AND METHODS}

\section{Data}

Milk samples used in the present study originated from 76 Irish herds collected between January 2013 and December 2015, inclusive; 174,062 milk samples from 10,394 dairy cows were collected.

Sixty-nine of the aforementioned 76 farms were commercial herds located in the Munster region of Ireland; the average herd size was 126 cows. Animals in the commercial herds were milked twice a day, at approximately $0700 \mathrm{~h}$ (a.m.) and again at approximately 1500 h (p.m.), and a combined a.m.+p.m. individual milk sample was sporadically collected and sent to the laboratory of Teagasc Animal and Grassland Research and Innovation Center (Moorepark, Fermoy, Co. Cork, Ireland) for mid-infrared spectroscopy analysis. On average, 1,249 samples were analyzed each month. Milk yield of the commercial farms represented the entire daily milk produced during the test-day recording. The average number of collected milk samples per cow was 5.15 , and 14,873 lactation records were available.

The remaining 7 farms were operated by Teagasc Animal and Grassland Research and Innovation Center (Moorepark, Fermoy, Co. Cork). In these research herds, 1,661 dairy cows were participating in various experimental treatments based on different feeding strategies and management practices, including various stocking rates, calving periods, and lengths of grazing period. All cows were fed a basal diet of grazed pasture, but at times were offered a quantity of concentrates according to the experimental treatment. Animals were milked twice a day (a.m. and p.m.) and milk yield was recorded at each milking session. Milk yield of the 2 daily milking sessions was summed to obtain daily milk yield. Individual milk samples were taken separately, once weekly, on consecutive p.m. and a.m. milkings. The average number of milk samples collected per cow was 78 , and the total number of lactations available was 2,956 .

Spectra information and milk chemical composition (i.e., concentrations of protein, casein, fat, lactose, total solids, and urea) of all milk samples were generated using the same MilkoScan FT6000 (Foss Electric A/S, Hillerød, Denmark) in the laboratory of Teagasc Animal and Grassland Research and Innovation Center (Moorepark, Fermoy, Co. Cork, Ireland) within a week of sample collection. The resulting milk spectra, containing 1,060 transmittance data points in the region between 900 and $5,000 \mathrm{~cm}^{-1}$, were stored. Somatic cell count of all samples was determined using a Fossomatic (Foss Electric A/S).

\section{Prediction of Milk Processing Phenotype}

Between the years 2013 and 2014, a calibration data set was generated from individual bovine milk samples collected from the 7 Irish research herds as described in detail by Visentin et al. (2015); data from cows milking in these 7 research farms also contributed to the larger data set in the present study. Full details on the development of the mid-infrared spectroscopy prediction models for milk technological traits, including RCT, $\mathrm{k}_{20}$, $\mathrm{a}_{30}, \mathrm{a}_{60}, \mathrm{HCT}, \mathrm{CMS}$, and $\mathrm{pH}$ are reported by Visentin et al. (2015). Rennet coagulation time represents the time required to induce milk coagulation after rennet addition, $k_{20}$ is the time between the gel development and 
the achievement of a width of $20 \mathrm{~mm}$ in the graph, and $\mathrm{a}_{30}$ and $\mathrm{a}_{60}$ are the widths of the graph after 30 and 60 min from rennet addition, respectively. Milk HCT was the time taken for milk within a hot oil bath at $140^{\circ} \mathrm{C}$ at an oscillating speed of $8 \mathrm{rpm}$ to start to flocculate. Casein micelle size represents the average diameter of casein micelles of a milk sample.

The developed prediction models (Visentin et al., 2015) were applied to the larger spectral data set of the current study to obtain the predicted milk processing phenotypes. Briefly, spectral data of the present study were converted from transmittance to absorbance by taking the $\log _{10}$ of the reciprocal of the transmittance, and spectral wavelengths with low signal-to-noise ratio $\left(1,580-1,710 \mathrm{~cm}^{-1}\right.$ and $\left.2,990-3,690 \mathrm{~cm}^{-1}\right)$ were discarded. Principal component analysis (PROC PRINCOMP; SAS Institute Inc., Cary, NC) was performed on the resulting edited spectra and the Mahalanobis distance from the centroid of the cluster of the samples included in the calibration data set was calculated. Spectra with a Mahalanobis distance greater than the $97.5 \%$ percentile of a $\chi^{2}$ distribution with 4 (i.e., lowest number of principal component whose eigenvalues was greater than 1) degrees of freedom were considered outliers and discarded. Following these edits, 157,192 spectra from 10,112 dairy cows remained, and the prediction models were applied to these spectra to generate predicted values for RCT, $\mathrm{k}_{20}, \mathrm{a}_{30}, \mathrm{a}_{60}, \mathrm{HCT}$, CMS, and $\mathrm{pH}$.

\section{Data Editing}

Only records between 5 and 305 DIM from parities $\leq 10$ were retained. Obvious data errors for predicted $\mathrm{RCT}, \mathrm{k}_{20}, \mathrm{a}_{30}, \mathrm{a}_{60}, \mathrm{HCT}, \mathrm{CMS}$, and $\mathrm{pH}$ and the milk production traits (i.e., milk yield, SCC, and concentrations of protein, fat, casein, lactose, total solids, and urea) were discarded. Somatic cell score (SCS) was calculated as $\log _{10}(\mathrm{SCC} / 1,000)$. Subsequently, records greater than 3 standard deviations from the mean of each trait were discarded. Cow breed composition was defined as the proportion of Holstein, Friesian, Jersey, Montbéliarde, Norwegian Red, and "other." Two contemporary groups were generated: (1) experimental treatment-test-date for milk samples from cows in the research herds; and (2) herd-test-date for milk samples from cows in the commercial herds. Only contemporary groups with at least 10 observations were retained. Following all these edits, 136,807 milk samples from 16,543 lactations from 9,824 dairy cows were available for further analyses.

Coefficients of general heterosis and recombination loss were calculated for each cow as described by VanRaden and Sanders (2003):

$$
\text { Heterosis }=1-\sum_{i=1}^{n} \text { sire }_{i} \times d a m_{i}
$$

and

$$
\text { Recombination loss }=1-\sum_{i=1}^{n} \frac{\operatorname{sire}_{i}^{2}+d a m_{i}^{2}}{2}
$$

where sire $_{i}$ and $d a m_{i}$ are the proportion of genes of the breed $i$ in the sire and the dam, respectively.

\section{Data Analysis}

Variance components for milk processing characteristics, milk yield, and milk composition were estimated using random regression models fitted across lactation in ASREML (Gilmour et al., 2011). The pedigree of all animals was traced back at least 4 generations (where available), and comprised 41,232 animals. The data were divided into 10 groups based on days postcalving as 5 to 30 DIM, 31 to 60 DIM, 61 to 90 DIM, ..., 241 to 270 DIM, and 271 to 305 DIM. Within group, the estimated residual variance was assumed homogeneous, whereas between groups, the estimated residual variance could be heterogeneous. No residual covariance was assumed to exist among groups. The fitted model was

$$
\begin{aligned}
y_{i j k l m o p n q}= & \text { Cont__roup }_{i}+\text { Session }_{j}+\sum_{i=1}^{k} \text { Breed }_{k}+\text { Het }_{l} \\
& + \text { Rec }_{m}+\sum_{i=1}^{n} \text { Par }_{o} b_{n} \text { DIM }^{n}+\sum_{i=1}^{n} \operatorname{Cow}_{p} b_{n} \text { DIM }^{n} \\
& +\sum_{i=1}^{n} \text { PEwithin }_{p} b_{n} \text { DIM }^{n}+\text { PEacross }_{p}+e_{i j k l m o p n q}
\end{aligned}
$$

where $y_{i j k l m o p n q}$ is RCT, $\mathrm{k}_{20}, \mathrm{a}_{30}, \mathrm{a}_{60}, \mathrm{HCT}, \mathrm{CMS}, \mathrm{pH}$, test-day milk yield, protein $\%$, fat $\%$, casein $\%$, lactose $\%$, urea $(\mathrm{mg} / \mathrm{dL})$, and SCS for animal $p$; Cont_group is the fixed effect of the $i$ th contemporary group $(5,709$ classes); Session $_{j}$ is the fixed effect of the $j$ th class of milking session (3 classes: a.m., p.m., or combined a.m.+p.m.); Breed $_{k}$ is the fixed effect of the $k$ th proportion of the $k$ th breed ( 5 breed proportions: Friesian, Jersey, Montbéliarde, Norwegian Red, and "other," all treated separately as continuous variables); Het $_{l}$ is the fixed effect of the $l$ th class of coefficient of heterosis (12 classes: $0,>0$ and $\leq 0.1, \ldots,>0.9$ and $<1,1) ; \operatorname{Rec}_{m}$ is the fixed effect of the $m$ th class of coefficient of recombination loss (12 classes: $0,>0$ and $\leq 0.1, \ldots,>0.9$ and $<1,1) ;$ Par $_{o}$ is the fixed effect of the oth class of parity 
(5 classes: $1,2,3,4, \geq 5) ; b_{n}$ is the $n$ th-order Legendre polynomial of DIM; $C_{0} w_{p}$ is the random effect for the additive genetic effect of the $p$ th animal; PEwithin $n_{p}$ is the random effect for the within-lactation permanent environmental effect of the $p$ th animal; PEacross $p$ is the random effect for the across-lactation permanent environmental effect of the $p$ th animal; and $e_{i j k l m o p n q}$ is the residual term.

The most parsimonious order of the fixed Legendre polynomial was evaluated based on visual inspection of the resulting lactation profile for the different polynomial orders for each trait studied. In all instances, a third-order Legendre polynomial was the most appropriate, with minimal difference detected from the lactation profiles generated from higher-order polynomials. To select the most parsimonious order for the random Legendre polynomial, different combinations of covariance functions were tested. The first model included a first-order Legendre polynomial fitted only to the additive genetic effect. The second model considered a first-order Legendre polynomial fitted also to the within-lactation permanent environmental effect. In the subsequent models, the polynomial order was increased incrementally by one unit with the order of the additive genetic effect being increased first, followed then by the within-lactation permanent environmental effect. The criteria set to select the most parsimonious order of the random Legendre polynomials were (1) the log-likelihood ratio test of 2 nested models (Wilks, 1938), (2) the Akaike information criterion, and (3) the eigenvalues of the additive genetic (co)variance matrix to quantify the contribution of the highest polynomial order to the entire genetic variance. A third-order Legendre polynomial on the additive genetic effect and on the within-lactation permanent environmental effect minimized the Akaike information criterion and maximized model log-likelihoods.

Genetic covariance function coefficients from the random regression analyses were calculated as

$$
\delta^{2}=\boldsymbol{\Phi} \mathbf{K} \boldsymbol{\Phi}^{\prime},
$$

where $\delta^{2}$ is the $301 \times 301($ co)variance matrix for the predicted milk technological trait, milk yield and milk chemical composition trait; $\boldsymbol{\Phi}$ is the $301 \times n$ matrix of Legendre polynomial of DIM regression coefficients; and $\mathbf{K}$ is the $n \times n$ estimated additive genetic (or within lactation permanent environmental effect) (co)variance matrix of the random polynomial coefficient. Standard errors of the heritability estimates were calculated using a Taylor series expansion as outlined in Fischer et al. (2004).
Genetic correlations between milk processing traits, milk yield, and milk chemical composition were calculated using a series of bivariate random regression models in ASREML (Gilmour et al., 2011) using the statistical model previously described for the univariate analyses. Residual groups were as defined in the univariate analyses, but residual covariances between traits within residual group were estimated. To achieve model convergence, the polynomial order of the random terms was reduced to a quadratic polynomial. Standard errors of the genetic correlations were estimated as outlined in Falconer and MacKay (1996).

For each studied trait, eigenvalues and eigenvectors were calculated from the additive genetic covariance matrix using PROC IML (SAS Institute Inc.), and eigenfunctions were calculated as the product of the eigenvectors and the Legendre polynomial coefficients matrix.

In a supplementary analysis, the heritability and repeatability of milk yield and each of the milk processing and composition traits were calculated using a univariate repeatability animal linear mixed model. Fixed effects fitted were the same as in the model previously described, but replacing the sets of fixed-effects Legendre polynomial coefficients with stage of lactation (10 classes: 5-30 DIM, 31-60 DIM, ..., 241-270 DIM, and 271-305 DIM) as per Visentin et al. (2017).

The effect of genetic selection for milk processability on milk yield, and vice versa, was undertaken using selection index theory. An economic weight of 1 was applied to milk yield, which was the only goal trait. (Co) variance components used in the selection index were those estimated in the present study averaged across all DIM from the bivariate random regression models; phenotypic correlations were those reported by Visentin et al. (2017). A restriction selection index was used to quantify the weighting required on the milk processing trait(s) of interest to halt any indirect deterioration due to selection on milk yield. The relative emphasis on an individual trait $i$ was calculated as in Berry (2015):

$$
\text { Emphasis }_{i}=\frac{\left|a_{i} \times \sigma_{i}\right|}{\sum_{j=1}^{n}\left|a_{j} \times \sigma_{j}\right|},
$$

where $a_{i}$ and $a_{j}$ are the economic weight for the traits $i$ and $j$, respectively, and $\sigma_{i}$ and $\sigma_{j}$ are the genetic standard deviations for traits $i$ and $j$, respectively. Selection index theory was also used to quantify the number of progeny or number of lactations per cow required to achieve a given level of reliability for a milk processing trait of interest. 
Table 1. Number of samples (n), mean, phenotypic standard deviation (SD), heritability, repeatability (t), and coefficient of genetic variation (CV) for milk processing traits, milk yield, and milk composition post-editing

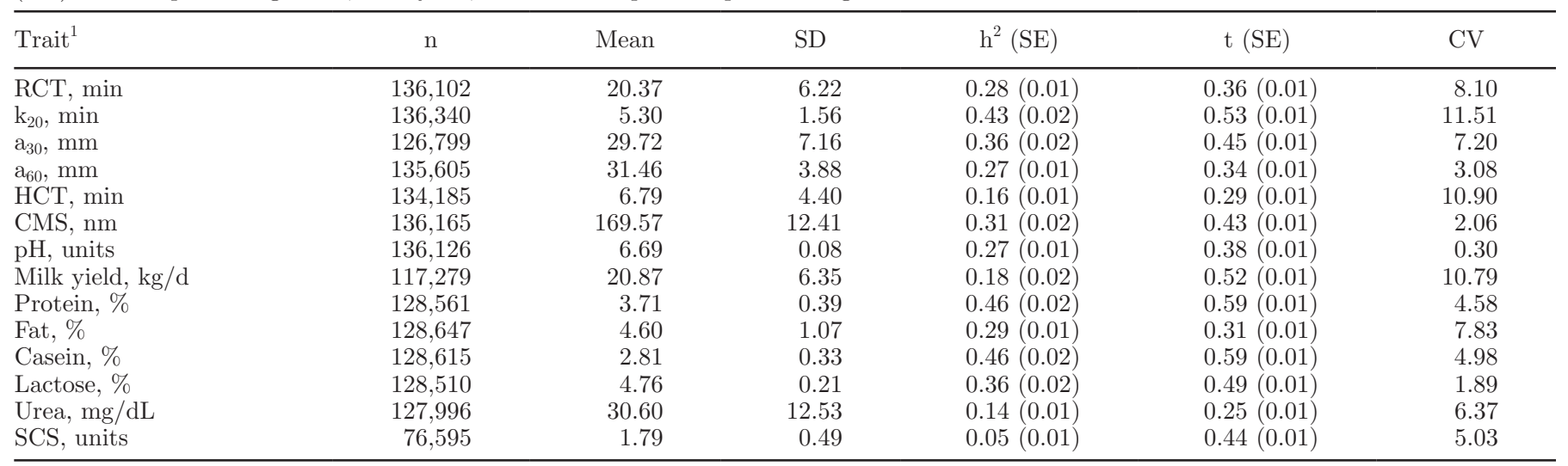

${ }^{1} \mathrm{RCT}=$ rennet coagulation time; $\mathrm{k}_{20}=$ curd-firming time; $\mathrm{a}_{30}=$ curd firmness at $30 \mathrm{~min} ; \mathrm{a}_{60}=$ curd firmness at 60 min; HCT $=$ heat coagulation time; $\mathrm{CMS}=$ casein micelle size; $\mathrm{SCS}=\log _{10}(\mathrm{SCC})$.

The proportion of genetic variation (i.e., coefficient of genetic variation, $C V_{G}$ ) in each milk processing trait independent of genetic merit for milk protein percentage was estimated as

$$
C V_{G}=\frac{\sqrt{\sigma_{G_{i}}^{2} \times\left(1-\mathrm{r}_{i, p r t}^{2}\right)}}{\left|\mu_{i}\right|} \%,
$$

where $\sigma_{G_{i}}^{2}$ is the estimated additive genetic variance of trait $i$ in the present study, $\mathrm{r}_{i, p r t}^{2}$ is the squared genetic correlation between trait $i$ and milk protein percentage estimated in the present study, and $\mu_{i}$ is the mean of trait $i$ in the present study.

\section{RESULTS}

Fewer records were available at the start and end of lactation $(8,329$ and 3,590 observations between 5 and 30 DIM and 271-305 DIM, respectively) relative to other stages, in which the number of records ranged between 11,002 (241-270 DIM) and 17,954 (91-120 DIM). The descriptive statistics, heritability, and repeatability (estimated using the repeatability animal model) of milk processing traits, milk yield, and milk composition are given in Table 1 . The coefficient of genetic variation for the milk technological traits varied from $3.08 \%\left(\mathrm{a}_{60}\right)$ to $11.51 \%\left(\mathrm{k}_{20}\right)$, with the exception of CMS $(2.06 \%)$ and milk pH $(0.30 \%$; Table 1$)$. A large coefficient of genetic variation $(10.79 \%)$ was evident for milk yield, whereas for milk composition, the coefficient of genetic variation ranged from $1.89 \%$ (lactose concentration) to $7.83 \%$ (fat concentration; Table 1). The heritability estimates for milk processing traits calculated using the repeatability animal model ranged from $0.16 \pm 0.01(\mathrm{HCT})$ to $0.43 \pm 0.02\left(\mathrm{k}_{20}\right)$, and the estimated heritability for the milk composition traits ranged from $0.05 \pm 0.01$ (SCS) to $0.46 \pm 0.02$ (protein and casein concentrations; Table 1).

\section{Genetic Variation and Heritability Estimates from the Random Regression Models}

The genetic standard deviation across lactation of all milk coagulation properties and CMS followed similar trends (Figure 1), reducing from the beginning of lactation to 31-60 DIM, and increasing thereafter. The genetic standard deviation ranged from $1.57 \pm 0.09$ $\min (43 \mathrm{DIM})$ to $2.24 \pm 0.29 \mathrm{~min}$ (305 DIM) for RCT, from $0.58 \pm 0.01 \mathrm{~min}(34 \mathrm{DIM})$ to $0.78 \pm 0.03 \mathrm{~min}$ (305 DIM) for $\mathrm{k}_{20}$, from $1.74 \pm 0.11 \mathrm{~mm}$ (44 DIM) to $4.12 \pm 0.62 \mathrm{~mm}(305 \mathrm{DIM})$ for $\mathrm{a}_{30}$, and from $0.81 \pm$ $0.03 \mathrm{~mm}$ (53 DIM) to $1.62 \pm 0.12 \mathrm{~mm}$ (305 DIM) for $\mathrm{a}_{60}$ (Figure 1). The genetic standard deviation for HCT decreased immediately after the onset of lactation (0.44 $\pm 0.02 \mathrm{~min} ; 21 \mathrm{DIM}$ ), but increased thereafter until 210 DIM (0.96 $\pm 0.03 \mathrm{~min})$, after which it decreased again (Figure 1). The genetic standard deviation for CMS was least at 45 DIM $(3.15 \pm 0.36 \mathrm{~nm})$, but increased thereafter until the end of lactation $(5.07 \pm 1.24 \mathrm{~nm}$; Figure 1). The genetic standard deviation of milk $\mathrm{pH}$ was small, ranging from $0.022 \pm 0.001$ at 56 DIM to $0.028 \pm 0.004$ at 5 DIM (Figure 1 ).

In general, heritability estimates for milk processing characteristics were the lowest in very early lactation (5-30 DIM), concurrent also with the greatest estimates of residual variances. The most heritable milk coagulation properties trait was $\mathrm{k}_{20}(0.26 \pm 0.02$ at 5 DIM to $0.57 \pm 0.02$ at 174 DIM), followed by $\mathrm{a}_{30}(0.16$ \pm 0.01 at 30 DIM to $0.56 \pm 0.02$ at 271 DIM $), a_{60}(0.13$ \pm 0.01 at $30 \mathrm{DIM}$ to $0.48 \pm 0.02$ at $271 \mathrm{DIM})$, and 

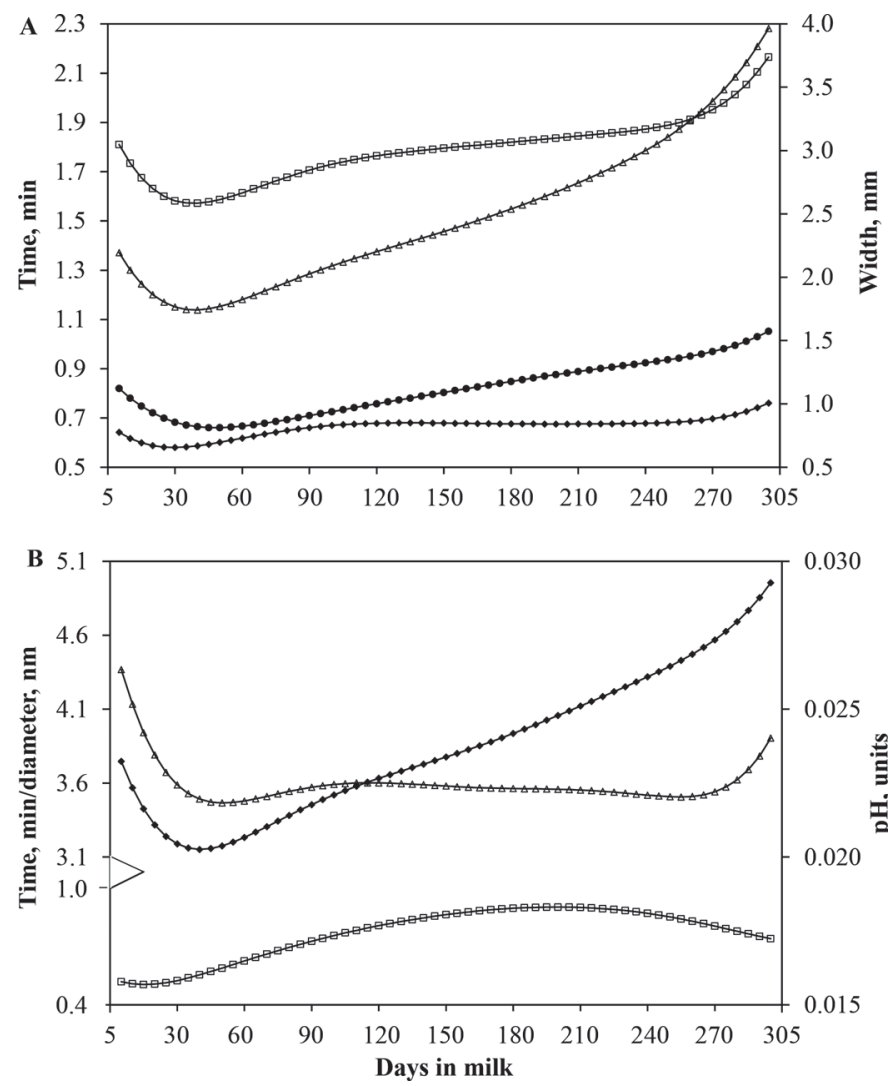

Figure 1. Genetic standard deviation (SE in parentheses) for (A) rennet coagulation time $(\square$, min; 0.08 to 0.29$)$, curd-firming time $(\diamond$, $\mathrm{min} ; 0.01$ to 0.03$)$, curd firmness $(\mathrm{mm})$ at $30 \mathrm{~min}(\Delta, \mathrm{mm} ; 0.10$ to $0.62)$, and curd firmness at $60 \mathrm{~min}(\bullet, \mathrm{mm} ; 0.02$ to 0.12$)$, and (B) heat coagulation time $(\square$, min; 0.01 to 0.08$)$, casein micelle size $(\bullet, \mathrm{nm}$; 0.35 to 1.24$)$, and $\mathrm{pH}$ ( $\Delta$, unitless; 0.001 to 0.004 ).

$\mathrm{RCT}(0.18 \pm 0.01$ at $26 \mathrm{DIM}$ to $0.38 \pm 0.02$ at 180 DIM; Figure 2). Heritability estimates for the remaining processing attributes ranged from $0.08 \pm 0.01$ (17 DIM) to $0.24 \pm 0.01$ (180 DIM) for HCT, $0.23 \pm 0.02$ (30 DIM) to $0.43 \pm 0.02$ (261 DIM) for CMS, and 0.20 \pm 0.01 (30 DIM) to $0.36 \pm 0.02$ (151 DIM) for $\mathrm{pH}$ (Figure 2). This therefore suggests that 8 to $56 \%$ of the adjusted phenotypic variability in the milk processing characteristics investigated in the present study were due to differences in additive genetic effects.

\section{Eigenvalues and Eigenfunctions}

The eigenfunction associated with the largest eigenvalue was almost linear but positive across all DIM for all milk processing characteristics (Figure 3), as well as for both milk yield and milk composition. In all instances, the eigenfunction associated with the second largest eigenvalue changed from negative to positive after mid-lactation (163-215 DIM, with the exception of milk $\mathrm{pH}$ where the change in sign occurred at 132
DIM). For all the studied traits, including milk yield and milk composition, by far the greatest proportion of the genetic variance was explained by the intercept term; the genetic variance explained by the largest eigenvalue varied from $82 \%\left(\mathrm{a}_{60}\right)$ to $92 \%$ (HCT). The proportion of genetic variation explained by the smallest eigenvalue varied from $1 \%$ (HCT, CMS, and $\mathrm{pH}$ ) to $2 \%\left(\mathrm{RCT}, \mathrm{k}_{20}, \mathrm{a}_{30}\right.$, and $\left.\mathrm{a}_{60}\right)$.

\section{Within-Trait Genetic Correlations}

In all instances, within trait genetic correlations weakened as the time between compared DIM lengthened but approached unity between adjacent DIM; nonetheless, all within-trait pairwise DIM genetic correlations were positive. Within-trait genetic correlations reached a minimum of $0.12 \pm 0.01$ for RCT, a minimum of $0.14 \pm 0.02$ for $k_{20}$, a minimum of $0.13 \pm 0.03$ for $\mathrm{a}_{30}$,
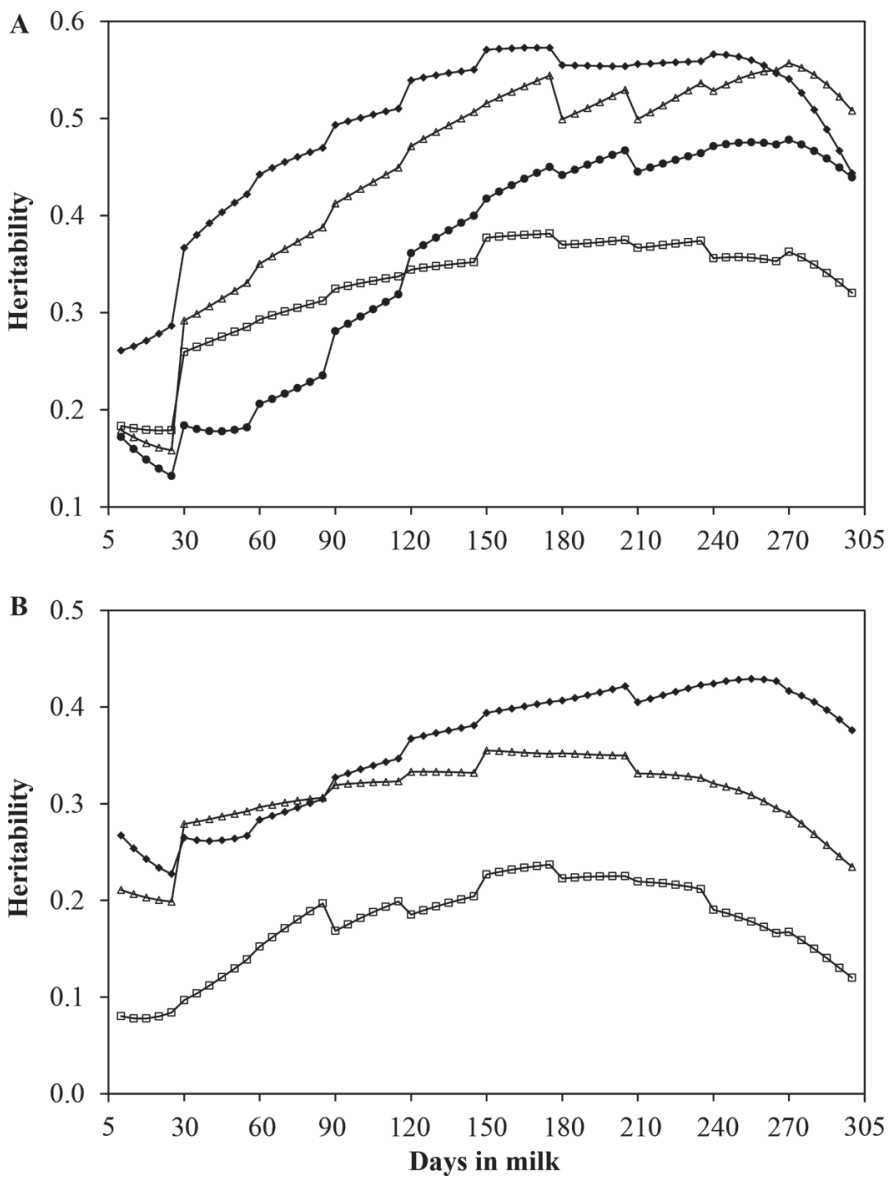

Figure 2. Heritability estimates for (A) rennet coagulation time $(\square$, min), curd-firming time $(\diamond$ min), curd firmness at $30 \mathrm{~min}(\Delta$, $\mathrm{mm}$ ), and curd firmness at $60 \mathrm{~min}(\bullet \mathrm{mm})$, and (B) heat coagulation time $(\square, \mathrm{min})$, casein micelle size $(\diamond, \mathrm{nm})$, and $\mathrm{pH}(\Delta$, unitless $)$. Standard error for the heritability estimates ranged between 0.01 and 0.03 . 

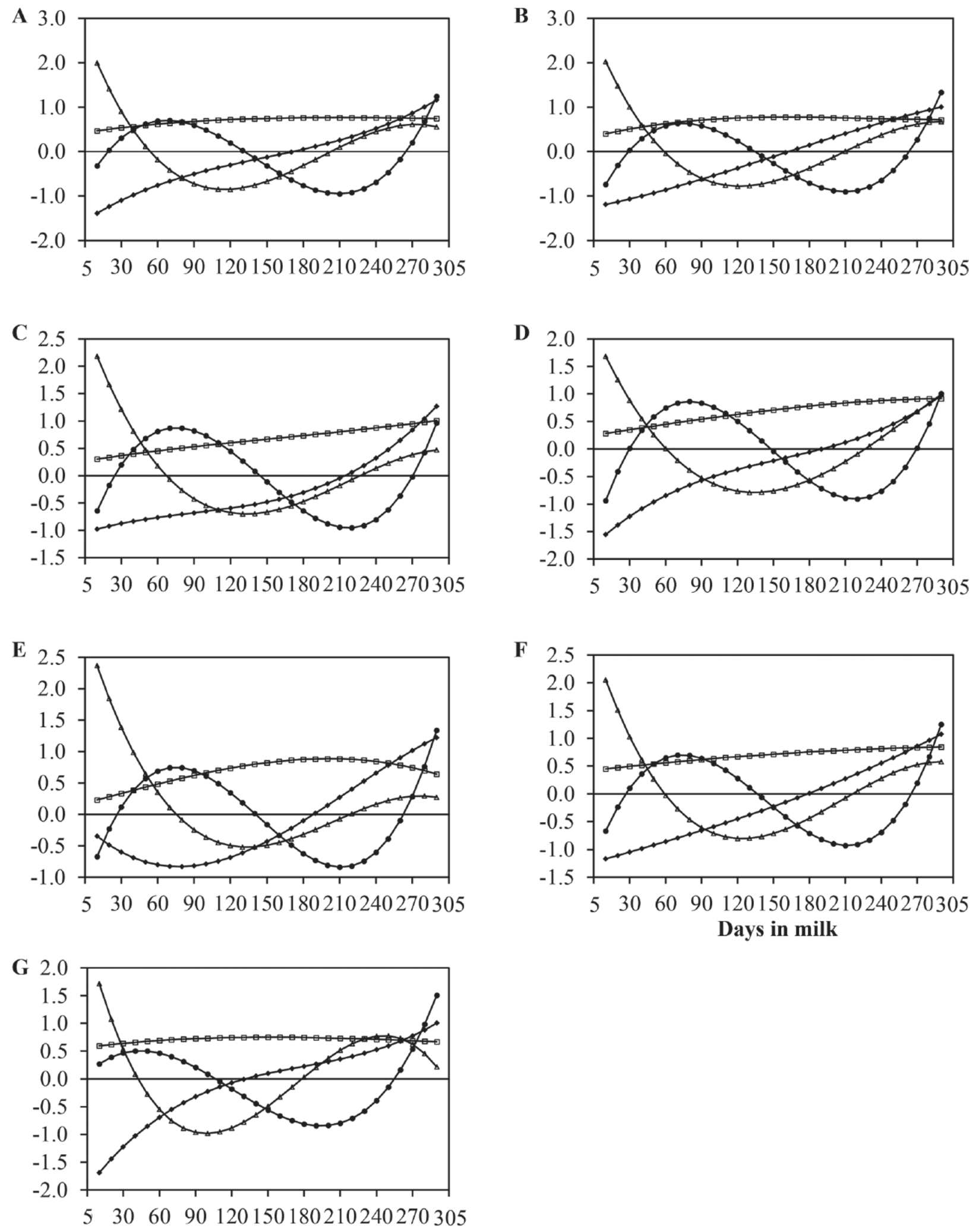

\section{Days in milk}

Figure 3. Eigenfunctions (y-axis, unitless) associated with the largest $(\square)$, first-middle $(\bullet)$, second-middle $(\Delta)$, and smallest $(\bullet)$ eigenvalue for (A) rennet coagulation time; (B) curd-firming time; (C) curd firmness at $30 \mathrm{~min}$; (D) curd firmness at 60 min; (E) heat coagulation time; (F) casein micelle size; and $(\mathrm{G}) \mathrm{pH}$. 
a minimum of $0.04 \pm 0.01$ for $\mathrm{a}_{60}$, a minimum of 0.26 \pm 0.01 for $\mathrm{HCT}$, a minimum of $0.31 \pm 0.01$ for CMS, and a minimum of $0.13 \pm 0.02$ for milk $\mathrm{pH}$ (Figure 4). Within-trait genetic correlation for milk composition traits had a minimum of $0.11 \pm 0.02$ and 0.13 \pm 0.02 for protein and fat concentrations, respectively (Supplemental Figure S1; https://doi.org/10.3168/ jds.2017-12642).

\section{Genetic Correlations Among Traits}

The genetic correlations among traits averaged across all DIM are reported in Table 2 and those among traits for each DIM are in Figures 5 and 6. Genetic correlations among the milk coagulation properties were generally strong, ranging from $0.69 \pm 0.01$ (160 DIM) to $0.85 \pm 0.02(5 \mathrm{DIM})$ between $\mathrm{RCT}$ and $\mathrm{k}_{20}$, and from $-0.81 \pm 0.03(5 \mathrm{DIM})$ to $-0.61 \pm 0.02(149 \mathrm{DIM})$ between RCT and $\mathrm{a}_{30}$ (Figure 5). Milk HCT and CMS were weakly correlated with all the other milk processing traits (Figure 5), whereas milk pH was strongly correlated only with RCT $(0.73 \pm 0.04$ at 5 DIM to $0.77 \pm 0.03$ at 305 DIM; data not shown). The correlations between milk yield and the milk processing traits were weak (from $0.07 \pm 0.10$ at 305 DIM to $0.21 \pm 0.04$ at 209 DIM with milk pH; Figure 6) to moderate (from $0.33 \pm 0.05$ at 5 DIM to $0.59 \pm 0.04$ at 303 DIM with $\mathrm{k}_{20}$, and from $-0.62 \pm 0.03$ at 283 DIM to $-0.20 \pm 0.06$ at 5 DIM with $\mathrm{a}_{30}$ ). Milk protein concentration, similar to casein concentration, was strongly correlated with both $\mathrm{k}_{20}(-0.84 \pm 0.02$ at 5 DIM to $-0.93 \pm 0.01$ at 305 DIM; Figure 6) and $\mathrm{a}_{30}(0.84 \pm 0.02$ at 21 DIM to 0.94 \pm 0.01 at 305 DIM; Figure 6$)$, but weakly correlated with HCT $(0.19 \pm 0.06$ at 36 DIM to $-0.27 \pm 0.07$ at 305 DIM; Figure 6).

\section{DISCUSSION}

The present study aimed to quantify the extent of genetic variability in milk processing characteristics predicted by mid-infrared spectroscopy from a large database of dairy cows reared mainly in a grazing dairy production system. Results indicated that genetic variation indeed exists for all milk processing traits, and that these milk quality features were only weakly to moderately genetically correlated with milk production and composition, with the exception of both $\mathrm{k}_{20}$ and $\mathrm{a}_{30}$ which were strongly ( -0.88 and 0.90 , respectively) correlated with the milk nitrogen constituents (i.e., protein and casein concentrations). Therefore, although genetic gain for milk processability could be achieved, the current selection objectives on production traits such as milk yield and fat and protein content (Miglior et al., 2005) are not fully exploiting the potential to genetically improve milk processability. Indeed, the coefficient of genetic variation in the milk processing features independent of genetic merit for protein concentration was $6.71 \%$ for RCT, $5.47 \%$ for $\mathrm{k}_{20}, 3.14 \%$ for $\mathrm{a}_{30}, 1.62 \%$ for $\mathrm{a}_{60}, 10.08 \%$ for $\mathrm{HCT}$, and $1.97 \%$ for CMS.

The use of covariance functions in the present study facilitated the modeling of the genetic (co)variances of milk processing characteristics along the entire lactation. Covariance functions have been extensively applied to the analysis of longitudinal data (van der Werf et al., 1998; Nobre et al., 2003; Berry et al., 2007). In the present study, milk processing attributes were modeled using a third-order Legendre polynomial, similar to Pretto et al. (2014), who used random regressions to model the genetic variation in RCT and $\mathrm{a}_{30}$ of dairy cows. Vallas et al. (2010), however, modeled both the additive genetic and permanent environmental variances using a second-order Legendre polynomial. The decomposition of the additive genetic (co)variance matrix into its eigenvectors and eigenvalues for all milk processing traits in the present study revealed that the smallest eigenvalue was explaining only a small proportion of the additive genetic variance. Therefore, the addition of the third-order polynomial did not dramatically improve the fit to the data and, in fact, may have over-fitted the extremities of the lactation, as purported by Legarra et al. (2004) when modeling growth curves of beef cattle.

\section{Extent of Genetic Variability in Milk Processing Characteristics}

With the exception of CMS and milk $\mathrm{pH}$, the coefficient of genetic variation in milk processing attributes, which in the present study ranged from $3.08 \%\left(\mathrm{a}_{60}\right)$ to $11.51 \%\left(\mathrm{k}_{20}\right)$, was comparable to the extent of genetic variation in milk yield $(10.79 \%)$ and milk protein, fat, and casein concentrations $(4.58,7.83$, and $4.98 \%$, respectively) also estimated in the present study. The existence of genetic variation in milk coagulation properties predicted by mid-infrared spectroscopy has previously been documented by Tiezzi et al. (2013) in a population of 16,089 Italian Holstein-Friesian dairy cows. The calculated coefficients of genetic variation based on the information provided by Tiezzi et al. (2013) were 8.43 and $19.33 \%$ for RCT and $\mathrm{a}_{30}$, respectively. To our knowledge, however, the extent of genetic variation in $\mathrm{HCT}$ and CMS has never been previously quantified.

Based on normal distribution theory, the expected mean performance of the top $20 \%$ of individuals relative to the mean is 1.4 standard deviation units; this equates to a reduction in milk RCT of $2.31 \mathrm{~min}, 3-\mathrm{mm}$ stronger curd, greater milk ability to withstand high- 

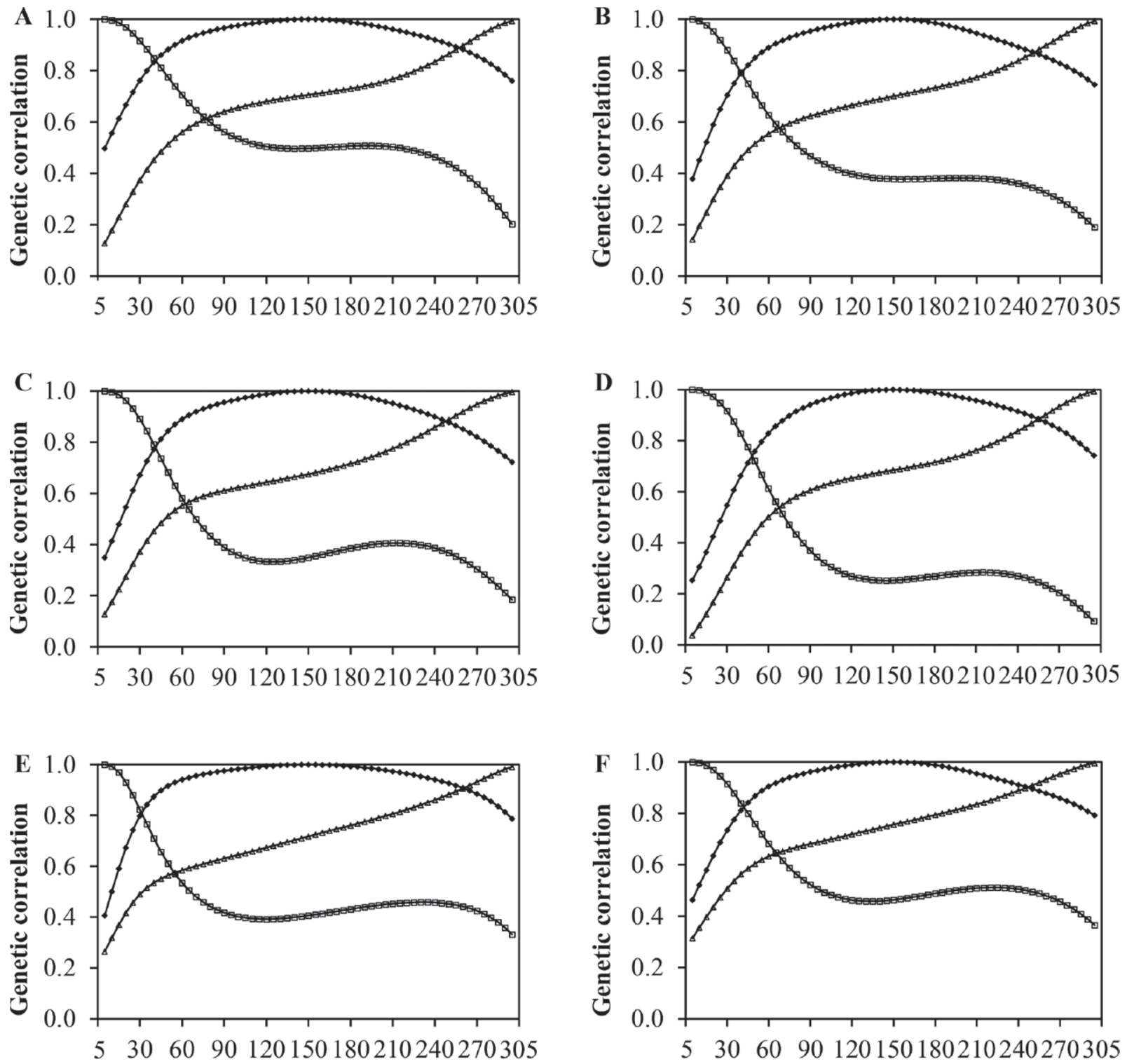

Days in milk

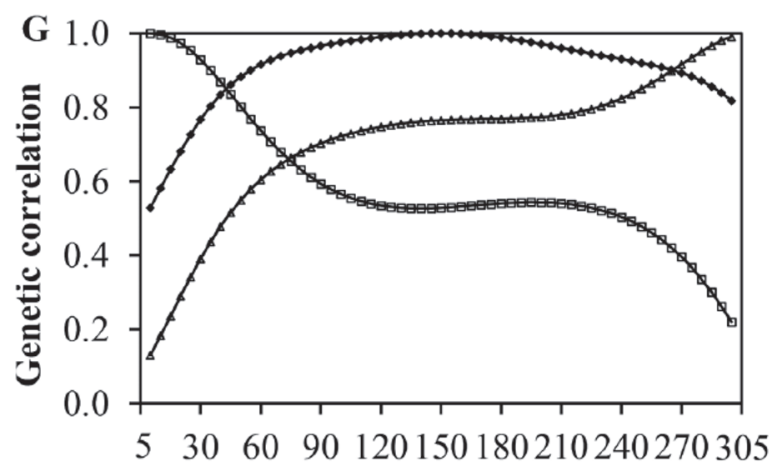

Days in milk

Figure 4. Within-trait genetic correlation between 5 DIM $(\square), 150$ DIM $(\diamond)$, and 305 DIM $(\Delta)$ and the rest of lactation for $($ A) rennet coagulation time; (B) curd-firming time; (C) curd firmness at $30 \mathrm{~min}$; (D) curd firmness at 60 min; (E) heat coagulation time; (F) casein micelle size; and $(\mathrm{G}) \mathrm{pH}$. Standard errors ranged between 0.00 and 0.02 . 

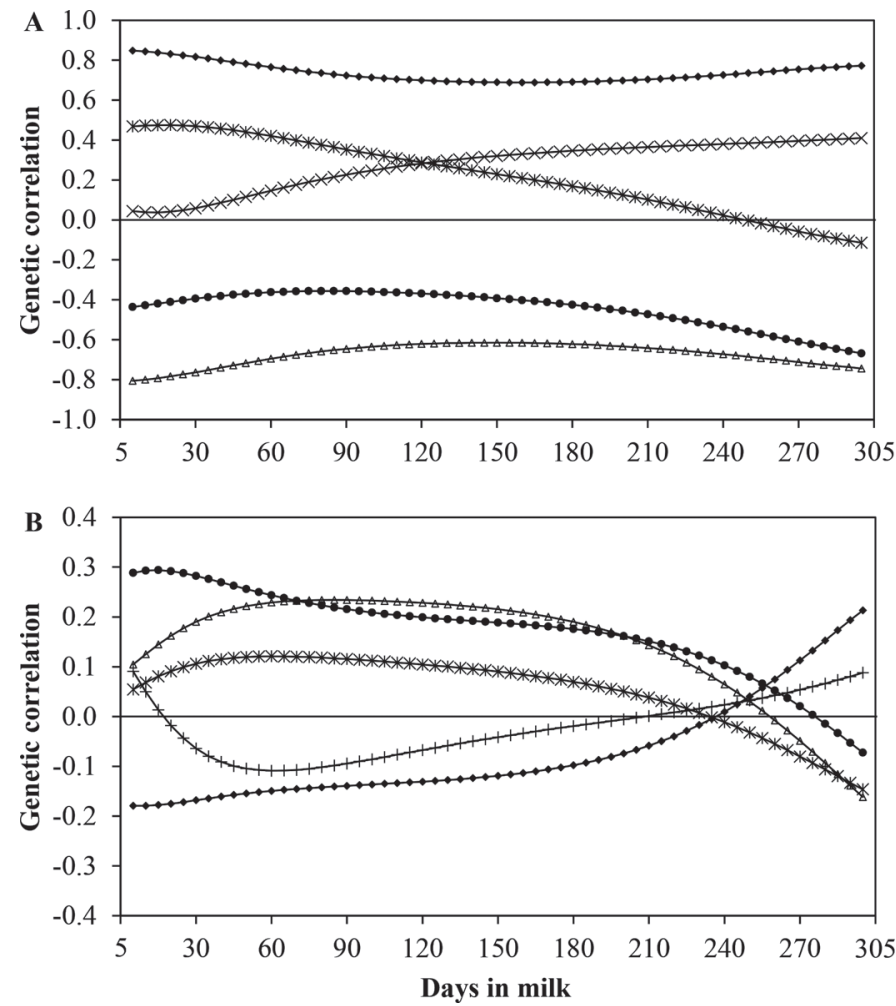

Figure 5. Genetic correlation (SE in parentheses) between (A) rennet coagulation time and curd-firming time ( $\$$; 0.01 to 0.03 ), curd firmness at $30 \mathrm{~min}(\Delta ; 0.01$ to 0.03$)$, curd firmness at $60 \mathrm{~min}(\mathbf{\bullet} ; 0.02$ to 0.07 ), heat coagulation time ( $\times ; 0.03$ to 0.12 ), and casein micelle size ( $* ; 0.03$ to 0.06$)$, and (B) heat coagulation time and curd-firming time ( $\$ 0.03$ to 0.10$)$, curd firmness at $30 \mathrm{~min}(\Delta ; 0.03$ to 0.11$)$, curd firmness at $60 \mathrm{~min}(\bullet ; 0.03$ to 0.11$)$, casein micelle size $(* ; 0.03$ to $0.10)$, and $\mathrm{pH}(+; 0.04$ to 0.13$)$.

temperature treatments (by $1 \mathrm{~min}$ ), and lower milk acidity (-0.03). Based on the positive phenotypic correlation between $\mathrm{a}_{30}$ and casein concentration estimated by Visentin et al. (2017) from the present data set, these top $20 \%$ individuals could yield $1.89 \%$ more cheese than the average individual, as casein concentration is a predictor of cheese yield (Van Slyke and Price, 1949). Assuming a milk fat concentration of $3.90 \%$ and a Cheddar cheese water content of $37.7 \%$ (Visentin et al., 2017), such an improvement corresponds to $0.21 \mathrm{~kg}$ of extra cheese $/ 100 \mathrm{~kg}$ of milk processed. Therefore, over the entire 305-d lactation the potential extra revenue is $€ 35 /$ cow, assuming a market price for Cheddar cheese of $€ 3.20 / \mathrm{kg}$ (IFA, 2016) and individual milk yield per lactation of $5,217 \mathrm{~kg}$ (Coffey et al., 2016). The main consequence of low milk HCT is fouling at the dairy plant level, resulting in reduced production efficiency and greater associated costs for energy consumption as well as machinery maintenance, which can account for up to $80 \%$ of the total production costs in processing (Bansal and Chen, 2006). Benefits therefore clearly ex-

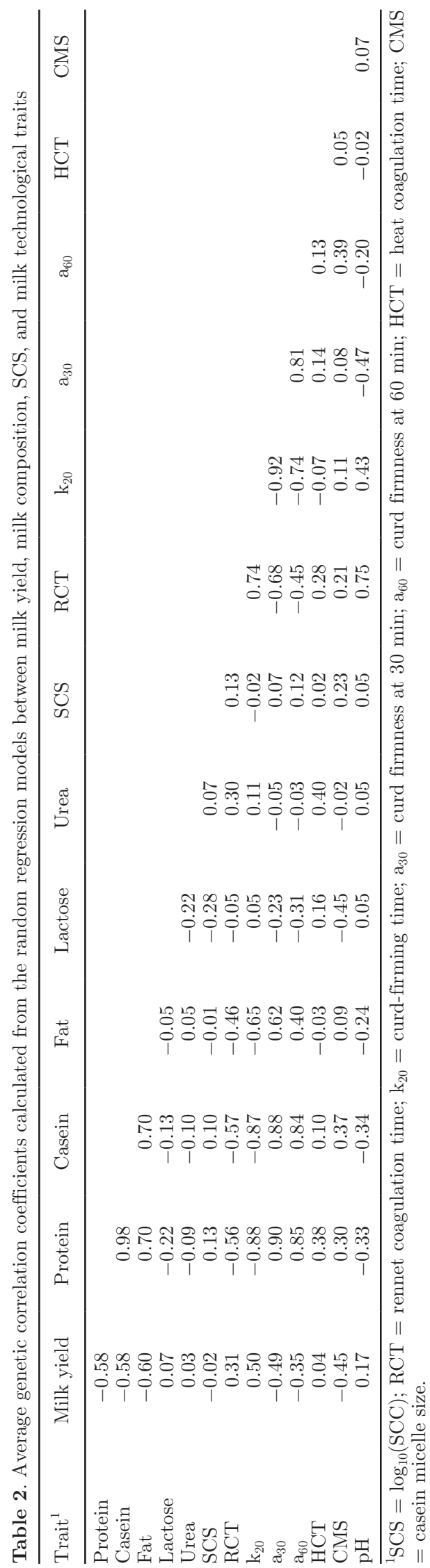

Journal of Dairy Science Vol. 100 No. 8, 2017 

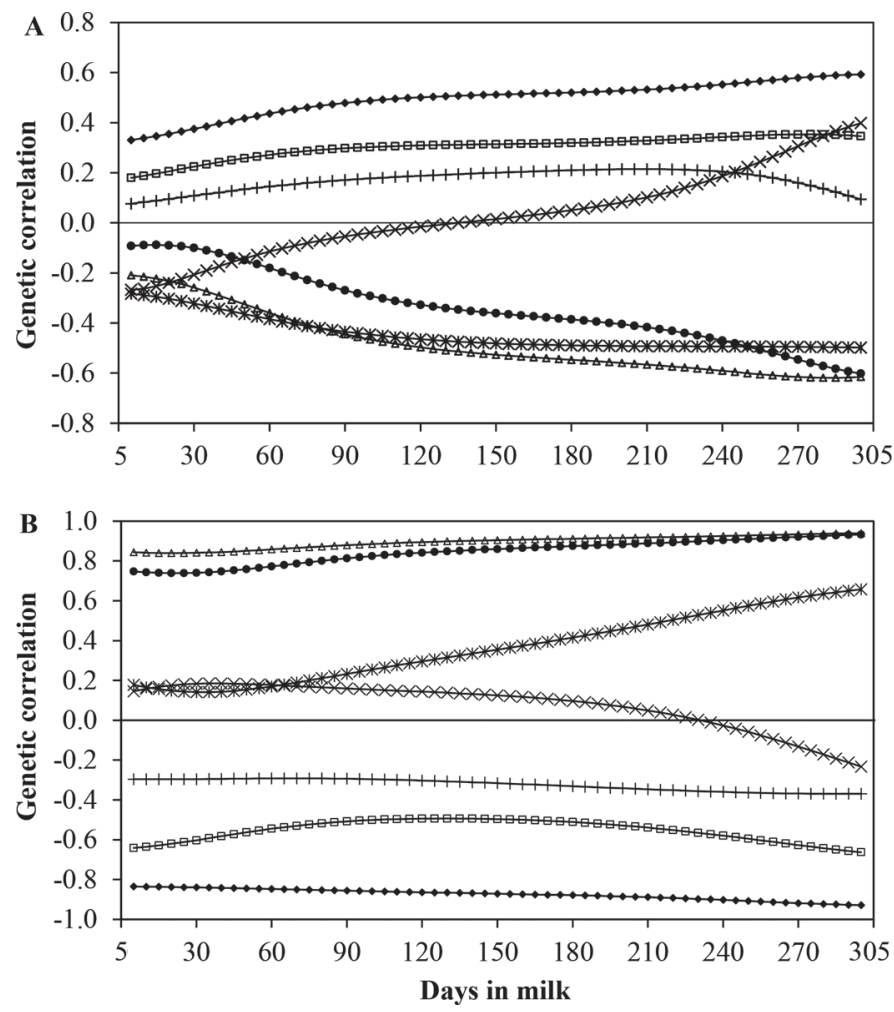

Figure 6. Genetic correlation (SE in parentheses) between (A) milk yield and rennet coagulation time ( $\square ; 0.03$ to 0.08$)$, curd-firming time ( $\quad 0.02$ to 0.05$)$, curd firmness at $30 \mathrm{~min}(\Delta ; 0.02$ to 0.06$)$, curd firmness at $60 \mathrm{~min}(\bullet ; 0.03$ to 0.07$)$, heat coagulation time $(\times ; 0.04$ to 0.12 ), casein micelle size ( $*$; 0.03 to 0.06$)$, and $\mathrm{pH}(+; 0.04$ to 0.10$)$, and (B) milk protein concentration and rennet coagulation time ( $\square$; 0.01 to 0.04 ), curd-firming time ( $\quad 0.01$ to 0.02 ), curd firmness at 30 $\min (\Delta ; 0.01$ to 0.02$)$, curd firmness at $60 \mathrm{~min}(\mathbf{\bullet} 0.01$ to 0.03$)$, heat coagulation time $(\times ; 0.02$ to 0.10$)$, casein micelle size $(* ; 0.01$ to 0.06$)$, and $\mathrm{pH}(+; 0.02$ to 0.06$)$.

ist to breeding programs for improved milk processing ability.

One obstacle to identifying animals divergent in genetic merit for milk processing characteristics (or most traits) is having sufficient records to achieve a high accuracy of selection; this requires routine access to the relevant phenotypic data, which can be augmented by accompanying genomic data, although the latter does still not preclude the necessity for phenotypic data. Based on the heritability and repeatability estimates from the present study, the number of progeny with one lactation record each required to achieve a reliability (i.e., squared accuracy of selection) of 0.70 is 31 for RCT, 19 for $\mathrm{k}_{20}, 24$ for $\mathrm{a}_{30}, 31$ for $\mathrm{a}_{60}, 56$ for HCT, 28 for $\mathrm{CMS}$, and 33 for $\mathrm{pH}$. The average parity number of cows in the present study was 3, suggesting that the reliability of the prediction of animal genetic merit is 0.49 for RCT, 0.63 for $\mathrm{k}_{20}, 0.57$ for $\mathrm{a}_{30}, 0.48$ for $\mathrm{a}_{60}$, 0.30 for HCT, 0.50 for CMS, and 0.46 for $\mathrm{pH}$. Because all individual cow (and bulk tank) milk samples are routinely subjected to mid-infrared spectroscopy analysis, generating these quantities of phenotypic records using mid-infrared spectroscopy-predicted milk processing characteristics (Visentin et al., 2017) should be achievable and, importantly, achievable at no marginal cost once the calibration equations are developed and validated.

\section{Breeding Strategies to Improve Product Consistency over Time}

Milk processing attributes, as well as output yield (i.e., cheese yield and whole and skim milk powder) have previously been documented to change with stage of lactation (Barłowska et al., 2014; Sneddon et al., 2016; Visentin et al., 2017). Because of the seasonal calving systems adopted by some countries such as Ireland (Berry et al., 2013), such temporal effects across lactation, compounded with seasonal effects (Visentin et al., 2017), manifest themselves as systematic temporal variability in milk quality across calendar months of the year. Such seasonal effects are minimized in many production systems through the adoption of year-round calving, thereby ensuring product yield and consistency all year round. Nonetheless, the cyclic variability in milk processing characteristics in seasonal-calving herds can represent a challenge for dairy processors (Downey and Doyle, 2007). Therefore, the possibility of altering the lactation profile for milk processing traits through animal breeding could be very advantageous to improve the efficiency of a manufacturing plant. The use of random regression models facilitates the estimation of breeding values for the trait under investigation across each DIM and thus facilitates the quantification of the potential to alter the lactation profile (Kirkpatrick et al., 1990). Because curd firmness is strong at the beginning (5-30 DIM) of lactation, but weakens to 31-60 DIM (Visentin et al., 2017), selection on the second eigenfunction for $\mathrm{a}_{30}$ could potentially reduce such a weakness with potential increased output losses (i.e., less cheese yield). Based on the evidence from the present study, however, the eigenfunction associated with the largest eigenvalue of all processing traits (as well as milk composition and yield) did not change sign over the entire lactation. Because the genetic variance attributable to the intercept term of the covariance function explained more than $80 \%$ of the genetic variance, strategies to alter the shape of the lactation profile, although still possible, would require greater selection pressure on the DIM (or eigenfunction) of relevance. The conclusion of a similar (set of) genes affecting milk processing characteristics across the entire lactation was substantiated by the generally strong within-trait genetic correlations 
across DIM. Nonetheless, simultaneous genetic change in 2 traits can still be achieved in spite of moderate to strong genetic correlations as evidenced by the ability to simultaneously improve milk production and reproduction performance, even if antagonistically correlated (Berry et al., 2014). Therefore, being able to alter the lactation profile for milk processing characteristics, in tandem with altering the height of the lactation profile, could be extremely beneficial in seasonal-calving production systems and help provide more consistent milk attributes across all seasons of the year.

\section{Consequences of Breeding for Milk Processability on Milk Production and Vice Versa}

Selection for increased milk production in dairy cows has predominated historical breeding objectives globally (Miglior et al., 2005) and contributed to more than double the lactation milk yield in 40 years (Oltenacu and Broom, 2010). Although production traits (milk, fat, and protein yields) remain a large component of current breeding objectives, emphasis is also placed on nonproduction, functional traits such as health and reproduction (Miglior et al., 2005). Whereas most countries have a negative weighting on milk yield in their national breeding goals, some countries, such as Latvia, South Africa, Switzerland, and the United States, still have a positive weight. Although the other countries have a negative weight on milk yield, the generally large positive weights on fat and protein yields imply a positive expected response to selection for milk yield. Evidence from the present study indicates antagonistic genetic correlations between milk yield and milk coagulation properties (ranging from 0.31 to 0.50 in absolute value), and these antagonistic genetic correlations corroborate previous studies in Finnish Ayrshire (Ikonen et al., 2004) and Holstein dairy cows (Vallas et al., 2010). The results from the present study suggest that, based on selection index theory, each unit (e.g., $\mathrm{kg}$ ) increase of daily milk yield is expected to lengthen RCT by $0.41 \mathrm{~min}$, and to weaken $\mathrm{a}_{30}$ by 0.79 $\mathrm{mm}$. Consequently, emphasis should be given to at least one milk coagulation properties trait to halt such deterioration, although the consequence will be a reduced rate of genetic gain in milk production. For example, if the breeding goal consisted solely of milk yield, to halt any deterioration in $\mathrm{a}_{30}$ would require an emphasis of $31 \%$ (relative to the emphasis given to milk yield). In such a scenario, the genetic gain in milk yield would be only $87 \%$ of the genetic response when only milk yield was included in the breeding goal. This emphasis on $\mathrm{a}_{30}$, however, would also be sufficient to halt any deterioration in RCT. Similarly, to achieve a genetic gain of 0.5 min in $\mathrm{HCT}$, an emphasis of $36 \%$ (relative to the emphasis given to milk yield) would need to be given to HCT, with negligible repercussions on the genetic response on milk yield. However, selection on both milk yield and HCT would still require emphasis also on at least one milk coagulation property to halt deterioration. The necessity of giving emphasis to a series of milk quality features, including technological characteristics, was suggested by Henchion et al. (2016) based on stakeholder involvement in a Delphi study. Indeed, an emphasis of $16 \%$ on a milk quality sub-index was advised by Henchion et al. (2016) to halt any deterioration on milk quality traits.

\section{CONCLUSIONS}

Our results clearly indicate that exploitable genetic variation exists for all milk processing traits, suggesting that breeding for improved milk processability is indeed achievable. Although the fitted random regression models provide estimated breeding values for every day of lactation, with the exception of the 2 peripheries of the lactation, the within-trait genetic correlations for all processing attributes were moderate, suggesting that the trait measured at any stage of lactation could be assumed the same trait. Therefore, unless there is interest in altering the lactation profile (e.g., in seasonal-calving herds) for milk processing characteristics, a simple repeatability model may suffice to undertake genetic evaluations for these traits.

\section{ACKNOWLEDGMENTS}

Funding for the current study was received from the Irish Department of Agriculture, Food and the Marine, Research Stimulus Fund project 11/SF/311, Breed Quality. Laboratory and technical support by Bernard Corrigan, Jim Flynn, Owen Kenny, Paula O'Connor, and Alan Hurley (Teagasc, Moorepark, Fermoy, Co. Cork, Ireland) is gratefully acknowledged.

\section{REFERENCES}

Bansal, B., and X. D. Chen. 2006. A critical review of milk fouling in heat exchangers. Compr. Rev. Food Sci. Food Saf. 5:27-33.

Barłowska, J., Z. Litwińczuk, and M. Kowal. 2014. Influence of production season and lactation stage on the technological suitability of milk from cows of various breeds fed in the TMR system. Ann. Anim. Sci. 14:649-661.

Bastin, C., L. Théron, A. Lainé, and N. Gengler. 2016. On the role of mid-infrared predicted phenotypes in fertility and health dairy breeding programs. J. Dairy Sci. 99:4080-4094.

Berry, D. P. 2015. Breeding the cow of the future: What do we need? Anim. Prod. Sci. 55:823-837.

Berry, D. P., B. Horan, M. O'Donovan, F. Buckley, E. Kennedy, M. McEvoy, and P. Dillon. 2007. Genetics of grass dry matter intake, energy balance, and digestibility in grazing Irish dairy cows. J. Dairy Sci. 90:4835-4845. 
Berry, D. P., J. F. Kearney, K. Twomey, and R. D. Evans. 2013. Genetics of reproductive performance in seasonal calving dairy cattle production systems. Ir. J. Agric. Food Res. 52:1-16.

Berry, D. P., E. Wall, and J. E. Pryce. 2014. Genetics and genomics of reproductive performance in dairy and beef cattle. Animal $8: 105-121$.

Cassandro, M., A. Comin, M. Ojala, R. Dal Zotto, M. De Marchi, L. Gallo, P. Carnier, and G. Bittante. 2008. Genetic parameters of milk coagulation properties and their relationship with milk yield and quality traits in Italian Holstein cows. J. Dairy Sci. 91:371376.

Chen, B., A. S. Grandison, and M. J. Lewis. 2016. Best use for milk-A review. I: Effect of breed variations on the physicochemical properties of bovine milk. Int. J. Dairy Technol. https://doi. org/10.1111/1471-0307.12352.

Coffey, E. L., B. Horan, R. D. Evans, and D. P. Berry. 2016. Milk production and fertility performance of Holstein, Friesian, and Jersey purebred cows and their respective crosses in seasonal-calving commercial farms. J. Dairy Sci. 99:5681-5689.

De Marchi, M., R. Dal Zotto, M. Cassandro, and G. Bittante. 2007. Milk coagulation ability of five dairy cattle. J. Dairy Sci. 90:39863992 .

De Marchi, M., V. Toffanin, M. Cassandro, and M. Penasa. 2014. Invited review: Mid-infrared spectroscopy as phenotyping tool for milk traits. J. Dairy Sci. 97:1171-1186.

Downey, L., and P. T. Doyle. 2007. Cow nutrition and dairy product manufacture - Implications of seasonal pasture-based milk production systems. Aust. J. Dairy Technol. 62:3-11.

Falconer, D. S., and T. F. C. MacKay. 1996. Introduction to Quantitative Genetics. 4th ed. Longman Group Ltd., London, UK.

Fischer, T. M., A. R. Gilmour, and J. H. J. van der Werf. 2004 Computing approximate standard errors for genetic parameters derived from random regression models fitted by average information REML. Genet. Sel. Evol. 36:363-369.

Gilmour, A. R., B. R. Cullis, S. J. Welham, and R. Thompson. 2011. ASREML Reference Manual. VSN International Ltd., Hemel Hempstead, UK

Henchion, M., M. McCarthy, V. C. Resconi, D. P. Berry, and S. McParland. 2016. Stakeholder involvement in establishing a milk quality sub-index in dairy cow breeding goals: A Delphi approach. Animal 10:878-891.

IFA. 2016. Irish Farmers' Association-Metadata. Accessed Dec. 19 2016. http://www.ifa.ie/market-reports/market-reports-7/.

Ikonen, T., K. Ahlfors, R. Kempe, M. Ojala, and O. Ruottinen. 1999. Genetic parameters for the milk coagulation properties and prevalence of noncoagulating milk in Finnish dairy cows. J. Dairy Sci. 82:205-214.

Ikonen, T., S. Morri, A.-M. Tyrisevä, O. Ruottinen, and M. Ojala. 2004. Genetic and phenotypic correlations between milk coagulation properties, milk production traits, somatic cell count, casein content, and pH of milk. J. Dairy Sci. 87:458-467.

Kirkpatrick, M., D. Lofsvold, and M. Bulmer. 1990. Analysis of the inheritance, selection and evolution of growth trajectories. Genetics 124:979-993.

Legarra, A., I. Misztal, and J. K. Bertrand. 2004. Constructing covariance functions for random regression models for growth in Gelbvieh beef cattle. J. Anim. Sci. 82:1564-1571.

McParland, S., and D. P. Berry. 2016. The potential of Fourier transform infrared spectroscopy of milk samples to predict energy intake and efficiency in dairy cows. J. Dairy Sci. 99:4056-4070.

Miglior, F., B. L. Muir, and B. J. Van Doormaal. 2005. Selection indices in Holstein cattle of various Countries. J. Dairy Sci. 88:12551263.

Murphy, S. C., N. H. Martin, D. M. Barbano, and M. Wiedmann. 2016. Influence of raw milk quality on processed dairy products How do raw milk quality test results relate to product quality and yield? J. Dairy Sci. 99:10128-10149.
Nobre, P. R. C., I. Misztal, S. Tsuruta, J. K. Bertrand, L. O. C. Silva, and P. S. Lopes. 2003. Analyses of growth curves of Nellore cattle by multiple-trait and random regression models. J. Anim. Sci. 81:918-926.

Oltenacu, P. A., and D. M. Broom. 2010. The impact of genetic selection for increased milk yield on the welfare of dairy cows. Anim. Welf. 19:39-49.

Poulsen, N. A., H. P. Bertelsen, H. B. Jensen, F. Gustavsson, M. Glantz, H. Lindmark Månsson, A. Andrén, M. Paulsson, C. Bendixen, A. J. Buitenhuis, and L. B. Larsen. 2013. The occurrence of noncoagulating milk and the association of bovine milk coagulation properties with genetic variants of the caseins in 3 Scandinavian dairy breeds. J. Dairy Sci. 96:4830-4842.

Poulsen, N. A., A. J. Buitenhuis, and L. B. Larsen. 2015. Phenotypic and genetic associations of milk traits with milk coagulation properties. J. Dairy Sci. 98:2079-2087.

Pretto, D., M. Vallas, E. Pärna, A. Tänavots, H. Kiiman, and T. Kaart. 2014. Short communication: Genetic correlation and heritability of milk coagulation traits within and across lactations in Holstein cows using multiple-lactation random regression animal models. J. Dairy Sci. 97:7980-7984.

Reid, M., M. O'Donovan, C. T. Elliott, J. S. Beiley, C. J. Watson, S. T. J. Lalor, B. Corrigan, M. A. Fenelon, and E. Lewis. 2015. The effect of dietary crude protein and phosphorus on grass-fed dairy cow production, nutrient status, and milk heat stability. J. Dairy Sci. 98:517-531.

Robertson, A. 1959. The sampling variance of the genetic correlation coefficient. Biometrics 15:469-485.

Sneddon, N. W., N. Lopez-Villalobos, S. R. Davis, R. E. Hickson, L. Shalloo, and D. J. Garrick. 2016. Supply curves for yields of dairy products from first-lactation Holstein Friesian, Jersey, and Holstein Friesian-Jersey crossbred cows accounting for seasonality of milk composition and production. Proc. New Zeal. Soc. Anim. Sci. $76: 139-143$

Tiezzi, F., D. Pretto, M. De Marchi, M. Penasa, and M. Cassandro. 2013. Heritability and repeatability of milk coagulation properties predicted by mid-infrared spectroscopy during routine data recording, and their relationships with milk yield and quality traits. Animal 7:1592-1599.

Tyrisevä, A.-M., T. Vahlsten, O. Ruottinen, and M. Ojala. 2004. Noncoagulation of milk in Finnish Ayrshire and Holstein-Friesian cows and effect of herds on milk coagulation ability. J. Dairy Sci. $87: 3958-3966$

Vallas, M., H. Bovenhuis, T. Kaart, K. Pärna, H. Kiiman, and E. Pärna. 2010. Genetic parameters for milk coagulation properties in Estonian Holstein cows. J. Dairy Sci. 93:3789-3796.

van der Werf, J. H. J., M. E. Goddard, and K. Meyer. 1998. The use of covariance functions and random regression for genetic evaluation of milk production. J. Dairy Sci. 81:3300-3308.

Van Slyke, L., and W. Price. 1949. Cheese. Orange Judd Publ. Co. Inc., New York, NY

VanRaden, P. M., and A. H. Sanders. 2003. Economic merit of crossbred and purebred US dairy cattle. J. Dairy Sci. 86:1036-1044.

Visentin, G., M. De Marchi, D. P. Berry, A. McDermott, M. A. Fenelon, M. Penasa, and S. McParland. 2017. Factors associated with milk processing characteristics predicted by mid-infrared spectroscopy analysis in a large database of dairy cows. J. Dairy Sci. 100:3293-3304

Visentin, G., A. McDermott, S. McParland, D. P. Berry, O. A. Kenny, A. Brodkorb, M. A. Fenelon, and M. De Marchi. 2015. Prediction of bovine milk technological traits from mid-infrared spectroscopy analysis in dairy cows. J. Dairy Sci. 98:6620-6629.

Wilks, S. S. 1938. The large-sample distribution of the likelihood ratio for testing composite hypothesis. Ann. Math. Stat. 9:60-62.

Williams, R. P. W. 2003. The relationship between the composition of milk and the properties of bulk milk products. Aust. J. Dairy Technol. 57:30-44. 